\title{
Analysis of organic acids in electron beam irradiated chestnuts \\ (Castanea sativa Mill.): Effects of radiation dose and storage time
}

Márcio Carocho $^{1}$, Lillian Barros ${ }^{1}$, Amilcar L. Antonio ${ }^{1,2,3}$, João C.M. Barreira ${ }^{1,4}$, Albino Bento $^{1}$, Iwona Kaluska ${ }^{5}$, Isabel C.F.R. Ferreira ${ }^{1, *}$

${ }^{1}$ CIMO/Escola Superior Agrária, Instituto Politécnico de Bragança, Apartado 1172, 5301-855 Bragança, Portugal.

${ }^{2}$ IST/ITN, Instituto Tecnológico e Nuclear, Estrada Nacional 10, 2686-953 Sacavém, Portugal.

${ }^{3}$ Departamento de Física Fundamental, Universidade de Salamanca, Plaza de la Merced, 37008 Salamanca, Spain.

${ }^{4}$ REQUIMTE, Departamento de Ciências Químicas, Faculdade de Farmácia da Universidade do Porto, Rua Jorge Viterbo Ferreira, 228, 4050-313 Porto, Portugal.

${ }^{5}$ Centre for Radiation Research and Technology, Institute of Nuclear Chem. and Technology, Dorodna str. 16, 03-195 Warsaw, Poland.

* Author to whom correspondence should be addressed (e-mail: iferreira@ipb.pt telephone $+351-273-303219$; fax +351-273-325405). 


\begin{abstract}
Since 2010, methyl bromide, a widely used fumigant was banned from the European Union under the Montreal Protocol guidelines, due to its deleterious effects on health and risk to the environment. Since then, many alternatives for chestnut conservation have been studied (hot water dip treatment being the most common), among them, electron beam irradiation has been proposed as being a safe, clean and cheap alternative. Herein, the effects of this radiation at different doses up to $6 \mathrm{kGy}$ and over storage up to 60 days in the amounts and profile of nutritionally important organic acids were evaluated. Chestnuts contained important organic acids with quinic and citric acids as main compounds. Storage time, which is traditionally well accepted by consumers, caused a slight decrease on quinic (13 to $9 \mathrm{mg} / \mathrm{g}$ ), ascorbic (1.2 to $0.8 \mathrm{mg} / \mathrm{g}$ ), malic (5 to $4 \mathrm{mg} / \mathrm{g}$ ), fumaric ( 0.4 to $0.3 \mathrm{mg} / \mathrm{g}$ ) and total organic (33 to $26 \mathrm{mg} / \mathrm{g}$ ) acids content. Otherwise, irradiation dose did not cause appreciable changes, either individually or in total (28 to $27 \mathrm{mg} / \mathrm{g})$ organic acid contents. Electron beam irradiation might constitute a valuable alternative for chestnut conservation.
\end{abstract}

Keywords: Castanea sativa; Food irradiation; Organic acids; UFLC-PDA 


\section{Introduction}

Organic acids are low weight molecules and are considered to be any organic carboxylic acids with a general structure R-COOH. Depending on their dissociation properties and the number of carboxylic groups, they can carry varying negative charges, thereby allowing the complexation of metal cations in solution (Dibner and Buttin, 2002; Jones, 1998). Citric, succinic, fumaric and malic acids play an important role in the Krebs cycle, being essential for human metabolism, but they have much more applications; citric acid is a crystal thickener in bones ( $\mathrm{Hu}$ et al., 2010), succinic acid is known to help on diabetes treatment (Pari and Saravanan, 2007), fumaric acid is effective against psoriasis and inflammation and can be used as a neuro and chemoprotector (Baati et al., 2011), and malic acid is reported to have a bactericidal effect (Raybaudi-Massilia et al., 2009).

Other organic acids, like oxalic and quinic acids are important metabolites in plants, displaying important roles on their metabolism, nonetheless oxalic acid is part of pharmaceutical preparations and used for desloughing of wounds and ulcers (Lian et al., 1999), while quinic acid is a stronger antioxidant than butylated hydroxyl toluene (BHT) (Hung et al., 2006). Shikimic acid takes part in the shikimate pathway, being essential for vegetable metabolism therefore producing L-phenylalanine and Ltryptophane witch are essential amino acids for humans (Krämer et al., 2003). Finally, ascorbic acid, one isoform of vitamin $\mathrm{C}$, is a naturally occurring organic acid which is essential against scurvy, a powerful antioxidant and quite effective against hypertension (Duffy et al., 1999).

Chestnuts are a widely consumed nut around the world, being China the biggest producer. Portugal represents $4 \%$ of its worldwide production with a gross weight of 22105 tons of chestnut in 2010, and an income of $15 \mathrm{M} €$ (INE, 2011). To maintain the 
quality and extend shelf-life of these nuts it is essential to apply adequate conservation methods. Until 2010, fumigation with methyl bromide $\left(\mathrm{CH}_{3} \mathrm{Br}\right)$ was the most common technique, until the European Union banned its use for allegedly being toxic to operators and for the negative effects on the environment (Official Journal of the EU, 2008). Following this decision, many other conservation techniques have been introduced, for instance, hot water dip, heat treatment and other fumigants, but they still represent quite a number of limitations and setbacks (Fields and White, 2002). Irradiation is recognized by international organizations as a valid conservation alternative and allowing pest free products (Bhat et al., 2008; Nagar et al., 2012; World Health Organization, 1991). The legally recognized ionized irradiation sources include gamma rays (high-energy photons) emitted by the radioactive elements cobalt-60 $\left({ }^{60} \mathrm{Co}\right)$ or cesium-137 $\left({ }^{137} \mathrm{Cs}\right)$ with high penetrating power, high-energy electron beams with limited penetration depth generated from electron accelerators operated at or below an energy level of $10 \mathrm{MeV}$ and x-rays generated from bombardment of a metal target by electrons at or below an energy level of $5 \mathrm{MeV}$ (Stefanova et al., 2010).

Our research group has proved that gamma radiation does not significantly alter the antioxidant, chemical and nutritional parameters of chestnuts for the tested doses, typical used for fruit conservation (Antonio et al., 2011; Barreira et al., 2012; Fernandes et al., 2011a; Fernandes et al., 2011b). Likewise, electron beam radiation proved to have slight effects on chestnuts antioxidant potential (Carocho et al., 2012a) and nutritional parameters (Carocho et al., 2012b). Other authors have studied the influence of irradiation in diverse food products (Girennavar et al., 2008), analysing the effects on different bioactive compounds including organic acids (Kim et al., 2004; Lisińska and Aniołowski, 1991; Reyes and Cisneros-Zevallos, 2007). Nevertheless, to our knowledge, there are no studies on the effects of electron beam irradiation on chestnuts 
organic acids, and given their importance in human nutrition, it would be beneficial that these compounds would not undergo any variations. In this study we report the effects of electron beam irradiation (doses of 0 - control, 0.5, 1, 3 and $6 \mathrm{kGy}$ ) and storage time (0- control, 30 and 60 days) on a series of organic acids, namely oxalic, quinic, malic, ascorbic, citric, fumaric, succinic and shikimic acid, using Ultra-Fast Liquid Chromatography and Photodiode Array detection (UFLC-PDA). The applied doses, which are in accordance with the legally permitted maximum doses (Stefanova et al., 2010), have the additional advantage of putatively ensure the biological safety. In fact, electron beam radiation proved to have an important effect in destroying the weevil larvae (Todoriki et al., 2006) reducing also yeast and mould.

\section{Materials and methods}

\subsection{Standards and reagents}

The standards of organic acids $(\mathrm{L}(+)$-ascorbic acid; citric acid; malic acid; oxalic acid; shikimic acid; succinic acid; fumaric acid; quinic acid) were purchased from Sigma (St. Louis, MO, USA). All other chemicals and solvents were of analytical grade and purchased from common sources. Water was treated in a Milli-Q water purification system (TGI Pure Water Systems, USA).

\subsection{Samples and samples irradiation}

Chestnuts (Castanea sativa Mill.) samples from Longal cultivar belonging to Castanha da Terra Fria PDO were collected in orchards located in Vinhais $\left(41^{\circ} 50^{\prime} \mathrm{N}, 7^{\circ} 00^{\prime} \mathrm{W}\right)$, Trás-os-Montes, in northeastern Portugal, in the second fortnight of October during the 
crop year of 2011. Well-formed chestnuts without any physical injury in the outer skin were selected among those collected randomly in the orchard.

They were divided in five groups: control (non-irradiated, $0 \mathrm{kGy}$ ), and the other four to be irradiated at $0.5,1,3$ and $6 \mathrm{kGy}$ with fifteen units per group.

The irradiation was performed at the INCT - Institute of Nuclear Chemistry and Technology - in Warsaw, Poland. To estimate the dose during the irradiation process three types of dosimeters were used, a graphite calorimeter, and two routine Gammachrome YR and Amber Perspex dosimeters, from Harwell company (U.K.). The irradiation took place in a e-beam irradiator of $10 \mathrm{MeV}$ of energy with a pulse duration of $5.5 \mu \mathrm{s}$, a pulse frequency of $440 \mathrm{~Hz}$, the average beam current was $1.1 \mathrm{~mA}$, the scan width of $68 \mathrm{~cm}$, the conveyer speed in the range $20-100 \mathrm{~cm} / \mathrm{min}$ and a scan frequency of $5 \mathrm{~Hz}$. The absorbed dose was $0.53,0.83,2.91 \mathrm{kGy}$ and $6.10 \mathrm{kGy}$, with an uncertainty of $20 \%$ for the two first doses, $15 \%$ for the third dose and $10 \%$ for the last dose. To read the Amber and Gammachrome YR dosimeters, spectrophotometric methods were used. For the Graphite calorimeter dosimeter the electrical resistance was read and converted in dose according to a previous calibrated curve. For simplicity, from now on we refer only the exact value for the dose: $0,0.5,1,3$ and $6 \mathrm{kGy}$.

After irradiation the samples were analysed immediately or stored at $4{ }^{\circ} \mathrm{C}$ (refrigerator) for 30 and 60 days. Before analyses, they were pilled, reduced to powder and lyophilized (FreeZone 4.5 model 7750031, Labconco, Kansas, USA).

\subsection{Organic acids extraction and analysis}

Samples $(\sim 2 \mathrm{~g})$ were extracted by stirring with $25 \mathrm{~mL}$ of meta-phosphoric acid $\left(25^{\circ} \mathrm{C}\right.$ at $150 \mathrm{rpm}$ ) for $45 \mathrm{~min}$ and subsequently filtered through Whatman No. 4 paper. Before analysis by UFLC-PDA, the samples were filtered through $0.2 \mu$ m nylon filters (Barros 
et al., 2013). The analysis was performed using a Shimadzu 20A series UFLC (Shimadzu Coperation). Separation was achieved on a SphereClone (Phenomenex) reverse phase $\mathrm{C}_{18}$ column $\left(5 \mu \mathrm{m}, 250 \mathrm{~mm} \times 4.6 \mathrm{~mm}\right.$ i.d) thermostatted at $35{ }^{\circ} \mathrm{C}$. The elution was performed with sulphuric acid $3.6 \mathrm{mM}$ using a flow rate of $0.8 \mathrm{~mL} / \mathrm{min}$. Detection was carried out in a PDA, using $215 \mathrm{~nm}$ and $245 \mathrm{~nm}$ (for ascorbic acid) as preferred wavelengths. The organic acids found were quantified by comparison of the area of their peaks recorded at $215 \mathrm{~nm}$ with calibration curves obtained from commercial standards of each compound. The results were expressed in mg per $\mathrm{g}$ of dry weight.

\subsection{Statistical analysis}

Organic acids extraction was performed in triplicate and each sample was injected two times in UFLC-PAD. The results are expressed as mean values \pm standard deviation $(\mathrm{SD})$.

Analysis of variance (ANOVA). ANOVA with Type III sums of squares was performed using the GLM (General Linear Model) procedure of the SPSS software, version 18.0. The dependent variables were analyzed using 2-way ANOVA, with the main factors "irradiation dose" (ID) and "storage time" (ST). The interaction effect among the factors $(\mathrm{ID} \times \mathrm{ST})$ was always significant; thereby, the two factors were evaluated simultaneously by the estimated marginal means plots for all levels of each single factor.

Principal components analysis (PCA). PCA was applied as pattern recognition unsupervised classification method. PCA transforms the original, measured variables into new uncorrelated variables called principal components. The first principal component covers as much of the variation in the data as possible. The second principal 
component is orthogonal to the first and covers as much of the remaining variation as possible, and so on (Patras et al., 2011). The number of dimensions to keep for data analysis was evaluated by the respective eigenvalues (which should be greater than one), by the Cronbach's alpha parameter (that must be positive) and also by the total percentage of variance (that should be as higher as possible) explained by the number of components selected. The number of dimensions considered for PCA was chosen in order to allow meaningful interpretations, and by ensuring their reliability.

\section{Results and discussion}

The effect of electron beam irradiation (ID) $(0.0,0.5,1.0,3.0$ and $6.0 \mathrm{kGy})$ and storage time (ST) (0, 30 and 60 days), as well as the interaction of both factors, were assessed by evaluating changes in organic acids composition. Studying the combined effect of both factors (ID and ST), it is possible to understand the influence of each single factor without having biased results.

Table 1 shows the organic acids composition data reported as mean value of each irradiation dose (ID) along the different storage times, as well as mean value of each storage time (ST) for the different irradiation doses.

At the beginning of the experiment, the main organic acids found in all treatment groups were quinic $(13 \pm 3 \mathrm{mg} / \mathrm{g})$ and citric $(12 \pm 3 \mathrm{mg} / \mathrm{g})$ acids. The obtained profiles were qualitatively similar to those presented in works dealing with the metabolite composition of chestnut upon cooking (Gonçalves et al., 2010; Ribeiro et al., 2007), despite the absence of cis-aconitic in the present samples. Nevertheless, the detected amounts are higher than those presented in the pointed publications, most likely due to the applied extraction method. ST $\times$ ID interaction was a significant $(P<0.001)$ source of variation for all the assayed compounds. Accordingly, no multiple comparisons tests 
could be performed. Nevertheless, from the analysis of the estimated margins mean plots some particular tendencies could be identified. For instance, quinic (Figure 1a) and ascorbic (Figure 1b) acids tended to be lower after 60 days of storage, while malic (Figure 1c) and fumaric (Figure 1d) acids leaned toward higher values in samples non submitted to storage. The variance caused by the assayed irradiation doses is slighter, and did not allow indication of any particular tendency. Moreover, it is known that heat induced reactions between nitrogen-free carboxylic acids and sugars are the most affecting parameters in organic acids, causing important changes in their contents (Piva et al., 2008; Ribeiro et al., 2007). In fact, neither ID nor ST seemed to exert high influence over organic acids profile. A similar study reported very small or no effects on the antioxidant constituents of mango fruit right after irradiation, despite a decrease in ascorbic acid levels along storage (Reyes and Cisneros-Zevallos, 2007). Lisińska and Aniołowski (2001), observed changes in citric and malic acid contents of three potato varieties exposed and non-exposed to gamma irradiation; the irradiated tubers exhibited a markedly increased content of these organic acids. Furthermore, Girennavar et al. (2008), concluded that low doses of electron beam irradiation has very little effect on the bioactive compounds and offers a safe alternative to existing postharvest treatments for the disinfection and decontamination of grapefruits.

Data obtained in the present study were evaluated through an unsupervised classification technique, namely principal components analysis (PCA). The plot of component loadings (Figure 2) indicates that the first two dimensions account for most of the variance of all quantified variables $(46.2 \%$ and $26.1 \%$, respectively). The selection of two dimensions was supported by the negative Cronbach's alpha values (0.078 , for the third dimension) and eigenvalues lower than one $(0.939$, for the third dimension) for higher dimensions. Regarding the relation between the objects and 
variables, it is clear (due to their positive correlation) that non-stored samples are characterized for having high malic and fumaric acids contents, while samples stored for 30 days have higher levels of quinic, ascorbic and citric acids.

However, the markers corresponding to 0,30 and 60 days were not separated in welldefined groups. The spatial distribution of markers resulting from different irradiation doses is even more entropic with, for instance, samples irradiated with $6 \mathrm{kGy}$ lying in the same area of non-irradiated samples (dashed lines in Figure 2).

Overall, from the analysis of the presented results, it was possible to conclude that organic acids composition was not significantly affected by the applied irradiation doses. The maintenance of organic acid levels is a desirable feature due to their protective role against various diseases, mainly those with oxidative stress basis (Silva et al., 2004a). From the conservation point of view, these are interesting results since the nature and concentration of organic acids are important factors influencing the organoleptic quality of fruit and vegetables, namely their flavour (Vaughan and Geissler, 1997) and constituting also important conservation indicators to evaluate food processing (Silva et al., 2004b). Furthermore, our previous reports also proved that electron beam kept other chestnuts quality parameters such as antioxidant levels (Carocho et al., 2012a) and nutritional compounds (Carocho et al., 2012b).

The authors declare that they not have any conflict of interest.

\section{Acknowledgements}

The authors thank ON.2/QREN/EU Project $n^{0} .13198 / 2010$ for financial support of this work, to Fundação para a Ciência e a Tecnologia (FCT, Portugal) and 
COMPETE/QREN/EU for financial support to CIMO (strategic project PEstOE/AGR/UI0690/2011). A.L. Antonio, L. Barros and J.C.M. Barreira also thank to FCT, POPH-QREN and FSE for their grants (SFRH/PROTEC/67398/2010, SFRH/BPD/4609/2008 and SFRH/BPD/72802/2010, respectively). Prof. A. Chmielewski, General Director of the Institute of Nuclear Chemistry and Technology, Warsaw, Poland, for allowing e-beam irradiations.

\section{References}

Antonio, A.L., Fernandes, Â., Barreira, J.C.M., Bento, A., Botelho, M.L., Ferreira, I.C.F.R. 2011. Influence of gamma irradiation in the antioxidant potential of chestnuts (Castanea sativa Mill.) fruits and skins. Food Chem. Toxicol. 49, 19181923.

Baati, T., Horcajada, P., Gref, R., Couvreur, P., Serre, C. 2011. Quantification of fumaric acid in liver, spleen and unrine by high-performance liquid chromatography coupled to photodiode-array detection. J. Pharm. Biomed. Anal. $56,758-762$.

Bhat, R., Sridhar, K.R., Young, C.-C., Bhagwath, A.A., Ganesh, S. 2008. Composition and functional properties of raw and electron beam-irradiated Mucuna pruriens seeds. Composition and functional properties of raw and electron beam-irradiated Mucuna pruriens seeds. Int. J. Food Sci. Technol. 43, 1338-1351.

Barreira, J.C.M., Antonio, A.L., Günaydi, T., Alkan, H., Bento, A., Botelho, M.L., Ferreira, I.C.F.R. 2012. Chemometric characterization of gamma irradiated chestnuts from Turkey. Rad. Phys. Chem. 81, 1520-1524. 
Barros, L., Pereira, C., Ferreira, I.C.F.R. 2013. Optimized analysis of organic acids in edible mushrooms from Portugal by ultra fast liquid chromatography and photodiode array detection. Food Anal. Method. 6, 309-316.

Carocho, M., Antonio, A.L., Barros, L., Bento, A., Botelho, M.L., Kaluska, I., Ferreira, I.C.F.R. (2012a). Comparative effects of gamma and electron beam irradiation on the antioxidant potential of Portuguese chestnuts (Castanea sativa Mill.). Food Chem. Toxicol. 50, 3452-3455.

Carocho, M., Barreira, J.C.M., Antonio, A.L., Bento, A., Kaluska, I., Ferreira, I.C.F.R. (2012b). Effects of electron beam radiation on nutritional parameters of Portuguese chestnuts (Castanea sativa mill.). J. Agric. Food Chem. 60, 77547760.

Dibner, J.J., Buttin, P. 2002. Use of organic acids as a model to study the impact of gut microflora on nutrition and metabolism. J. Appl. Poultry Res. 11, 453-463.

Duffy, S.J., Gokce, N., Holbrook, M., Huang, A., Frei, B., Jr, J.F.K., Vita, J.A. 1999. Treatment of hypertension with ascorbic acid. Lancet 354, 2048-2049.

Erhan, I., Bala, K., Joseph, M., Suresh, P. 2007. Electron beam radiation of dried fruits and nuts to reduce yeast and mould bioburden. J. Food Prot. 70, 981-985.

Fernandes, Â., Antonio, A.L., Barros, L., Barreira, J.C.M., Bento, A., Botelho, M.L., Ferreira, I.C.F.R. 2011a. Low dose $\gamma$-irradiation as a suitable solution for chestnut (Castanea sativa Miller) conservation: Effects on sugar, fatty acids and tocopherols. J. Agric. Food Chem. 59, 10028-10033.

Fernandes, Â., Barreira, J.C.M., Antonio, A.L., Bento, A., Botelho, M.L., Ferreira, I.C.F.R. 2011b. Assessing the effects of gamma irradiationand storage time in energetic value and in major individual nutrients of chestnuts. Food Chem. Toxicol. 49, 2429-2432. 
Fields, P.G., White, N.D.G. 2002. Alternatives to methyl bromide treatments for storedproduct and quarantine insects. Ann. Rev. Entomol. 47, 331-359.

Girennavar, B., Jayaprakasha, G.K., Mclin, S.E., Maxim, J., Yoo, K.S., Patil, B.S. 2008. Influence of Electron-Beam Irradiation on Bioactive Compounds in Grapefruits (Citrus paradisi Macf.). J. Agric. Food Chem. 56, 10941-10946.

Gonçalves, B., Borges, O., Costa, H.S., Bennett, R., Santos, M., Silva, A.P. 2010. Metabolite composition of chestnut (Castanea sativa Mill.) upon cooking: Proximate analysis, fibre, organic acids and phenolics. Food Chem. 122, 154-160.

Hu, Y.Y., Rawal, A., Schmidt-Rohr, K. 2010. Strongly bound citrate stabilizes the apatite nanocrystals in bone. Proc. Nat. Acad. Sci. 107, 22425-22429.

Hung, T.M., Na, M.K., Thuong, P.T., Su, N.D., Sok, D.E., Song, K.S., Seong, Y.H., Bae, K.H. 2006. Antioxidant activity of caffeoyl quinic acid derivatives from the roots of Dipascus asper wall. J. Ethnopharmacol. 108, 188-192.

INE-National Statistics Institute. 2011. Estatísticas Agrícolas 2010 (Portuguese Gorvernment) http://www.ine.pt/xportal/xmain?xpid=INE\&xpgid=ine_publicacoes\&PUBLICA COESpub_boui=123297571\&PUBLICACOESmodo=2.

Jones, D.L. 1998. Organic acids in the rizosphere-a critical review. Plant Soil 205, 2544.

Kim, B-H., Jang, A., Lee, S.O., Min, J.S., Lee, M. 2004. Combined effect of electronbeam (beta) irradiation and organic acids on shelf life of pork loins during cold storage. J. Food Prot. 67, 168-171.

Krämer, M., Bongaerts, J., Bovenberg, R., Kremer, S., Müller, U., Orf, S., Wubbolts, M., Raeven, L. 2003. Metabolic engineering for microbial production of shikimic acid. Metabol. Eng. 5, 277-283. 
Lian, H.Z., Mao, L., Ye, X.L., Miao, J. 1999. Simultaneous determination of oxalic, fumaric, maleic and succinic acids in tartaric and malic acids for pharmaceutical use by ion-supression reversed-phase high performance liquid chromatography. J. Pharm. Biomed. Anal. 19, 621-625.

Lisińska, G., Aniołowski, K. 1991. Organic acids in potato tubers: Part 2- The effect of gamma irradiation on citric and malic acid contents of potato tubers. Food Chem. 40, 207-212.

Nagar, V., Hajare, S.H., Saroj, S.D., Bandekar, J.R. 2012. Radiation processing of minimally processed sprouts (dew gram and chick pea): effect on sensory, nutritional and microbiological quality. Int. J. Food Sci. Technol. 47, 620-626.

Official Journal of the European Union. 2008. Comission Decision 753/2008:26-092008 .

Pari, L., Saravanan, R. 2007. Beneficial effect of succinic acid monoethyl ester on erythrocyte membrane bound enzymes and antioxidant status in streptozotocinnicotinamide induced type 2 diabetes. Chem.-Biol. Inter. 169, 15-24.

Patras, A., Brunton, N.P., Downey, G., Rawson, A., Warriner, K., Gernigon, G. 2011. Application of principal component and hierarchical cluster analysis to classify fruits and vegetables commonly consumed in Ireland based on in vitro antioxidant activity. J. Food Compos. Anal. 24, 250-256.

Piva, A., Mattia, C.D., Neri, L., Dimitri, L., Chiarini, G., Sacchetti, M.G. 2008. Heatinduced chemical, physical and functional changes during grape must cooking. Food Chem. 106, 1057-1065.

Raybaudi-Massilia, R.M., Mosqueda-Melgar, J., Martín-Belloso, O. 2009. Antimicrobial activity of malic acid against Listeria monocytogenes, Salmonella 
enteritidis and Escherichia coli $\mathrm{O} 157: \mathrm{H} 7$ in apple, pear and melon juices. Food Control 20, 105-112.

Reyes, L.F., Cisneros-Zevallos, L. 2007. Electron-beam ionizing radiation stress effects on mango fruit (Mangifera indica L.) antioxidant constituents before and during postharvest storage. J. Agric. Food Chem. 55, 6132-6139.

Ribeiro, B., Rangel, J., Valentão, P., Paula, B., Andrade, P.B., Pereira, J.A., Bölke, H, Seabra, R.M. 2007. Organic acids in two Portuguese Chestnut (Castanea sativa Miller) varieties. Food Chem. 100, 504-508.

Silva, B.M., Andrade, P.B., Valentão, P., Ferreres, F., Seabra, R.M., Ferreira, M.A. 2004a. Quince (Cydonia oblonga Miller) fruit (pulp, peel, and seed) and jam: antioxidant activity. J. Agric. Food Chem. 52, 4705-4712.

Silva, B.M., Andrade, P.B., Gonçalves, A.C., Seabra, R.M., Oliveira, M.B., Ferreira, M.A. 2004b. Influence of jam processing upon the contents of phenolics, organic acids and free amino acids in quince fruit (Cydonia oblonga Miller). Eur. Food Res. Technol. 218, 385-389.

Stefanova, R., Vasilev, N.V., Spassov, S.L. 2010. Irradiation of food, current legislation framework, and detection of irradiated foods. Food Anal. Methods 3, 225-252.

Todoriki, S., Hasan, M., Miyanoshita, A., Imamura, T., Hayashi, T. 2006. Assessment of electron beam-induced DNA damage in larvae of chestnut weevil, Curculio sikkimensis (Heller) (Coleptera: Curculionidae) using comet assay. Rad. Phys. Chem. 75, 292-296.

Vaughan, J.G., Geissler, C.A. 1997. The new Oxford book of food plants (p. xix). New York: Oxford University Press.

World Health Organization. 1991. Food Irradiation- A Technique for Preserving and Improving the Safety of Food. WHO, Geneva. 


\section{Legend to Figures}

Figure 1. Interactions between storage time and irradiation dose effects in chestnut samples (bars in each line represent standard deviation). Influence on quinic (a), malic (b), ascorbic (d) and fumaric (d) acids.

Figure 2. PCA biplot of objects and component loadings. 
Table 1. Composition in organic acids (mg/g dw) according with ID and ST $\left(\right.$ mean $\left.\pm \mathrm{SD}^{\mathrm{a}}\right)$. In each column, different letters mean significant differences.

\begin{tabular}{|c|c|c|c|c|c|c|c|c|}
\hline & & Oxalic & Quinic & Malic & Ascorbic & Citric & Fumaric & Total \\
\hline \multirow{4}{*}{ ST } & 0 days & $0.7 \pm 0.1$ & $13 \pm 3$ & $5 \pm 1$ & $1.2 \pm 0.3$ & $12 \pm 3$ & $0.4 \pm 0.1$ & $33 \pm 7$ \\
\hline & 30 days & $0.7 \pm 0.2$ & $15 \pm 2$ & $3 \pm 1$ & $1.3 \pm 0.3$ & $14 \pm 2$ & $0.25 \pm 0.05$ & $35 \pm 4$ \\
\hline & 60 days & $0.7 \pm 0.1$ & $9 \pm 2$ & $4 \pm 1$ & $0.8 \pm 0.3$ & $11 \pm 3$ & $0.30 \pm 0.04$ & $26 \pm 4$ \\
\hline & $P$-value $(\mathrm{n}=30)$ & 0.423 & $<0.001$ & $<0.001$ & $<0.001$ & $<0.001$ & $<0.001$ & $<0.001$ \\
\hline \multirow{6}{*}{ ID } & $0 \mathrm{kGy}$ & $0.8 \pm 0.1$ & $11 \pm 4$ & $4 \pm 1$ & $1.0 \pm 0.5$ & $11 \pm 2$ & $0.3 \pm 0.1$ & $28 \pm 7$ \\
\hline & $0.5 \mathrm{kGy}$ & $0.6 \pm 0.1$ & $14 \pm 4$ & $4 \pm 1$ & $1.3 \pm 0.5$ & $16 \pm 1$ & $0.3 \pm 0.1$ & $36 \pm 6$ \\
\hline & $1 \mathrm{kGy}$ & $0.8 \pm 0.1$ & $13 \pm 2$ & $4 \pm 1$ & $1.2 \pm 0.2$ & $13 \pm 1$ & $0.3 \pm 0.1$ & $32 \pm 3$ \\
\hline & 3 kGy & $0.7 \pm 0.1$ & $12 \pm 3$ & $4 \pm 1$ & $1.2 \pm 0.2$ & $14 \pm 2$ & $0.3 \pm 0.1$ & $33 \pm 5$ \\
\hline & 6. kGy & $0.8 \pm 0.1$ & $12 \pm 5$ & $3.4 \pm 0.4$ & $1.0 \pm 0.1$ & $10 \pm 1$ & $0.26 \pm 0.03$ & $27 \pm 6$ \\
\hline & $P$-value $(\mathrm{n}=18)$ & $<0.001$ & $<0.001$ & $<0.001$ & $<0.001$ & $<0.001$ & $<0.001$ & $<0.001$ \\
\hline $\mathrm{ID} \times \mathrm{ST}$ & $P$-value & $<0.001$ & $<0.001$ & $<0.001$ & $<0.001$ & $<0.001$ & $<0.001$ & $<0.001$ \\
\hline
\end{tabular}

${ }^{\mathrm{a}}$ Results are reported as mean value of each irradiation dose (ID) over the different storage times (ST) as well as mean value of all ST within each ID. Therefore, SD reflects values in those samples (under different ID or ST). 

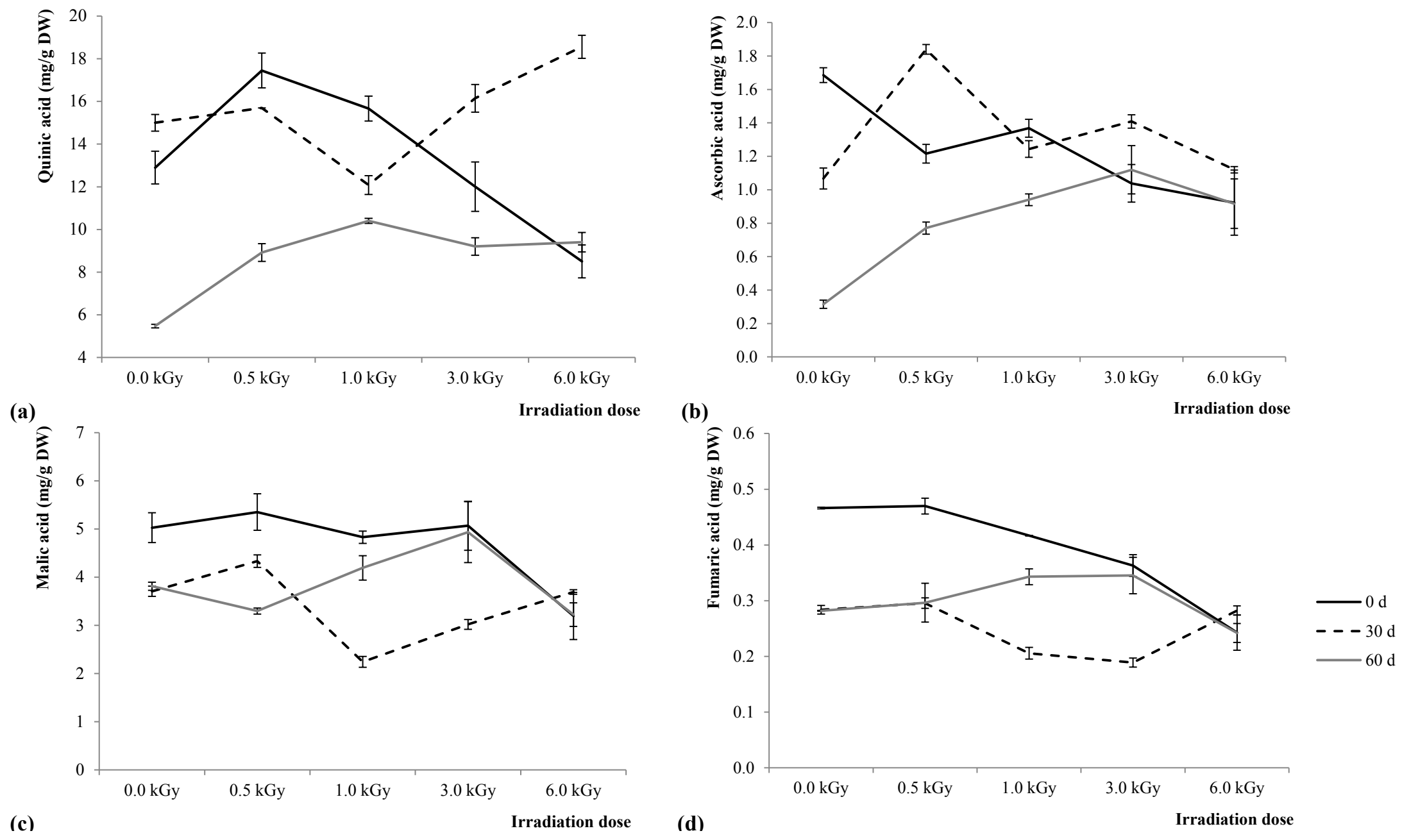


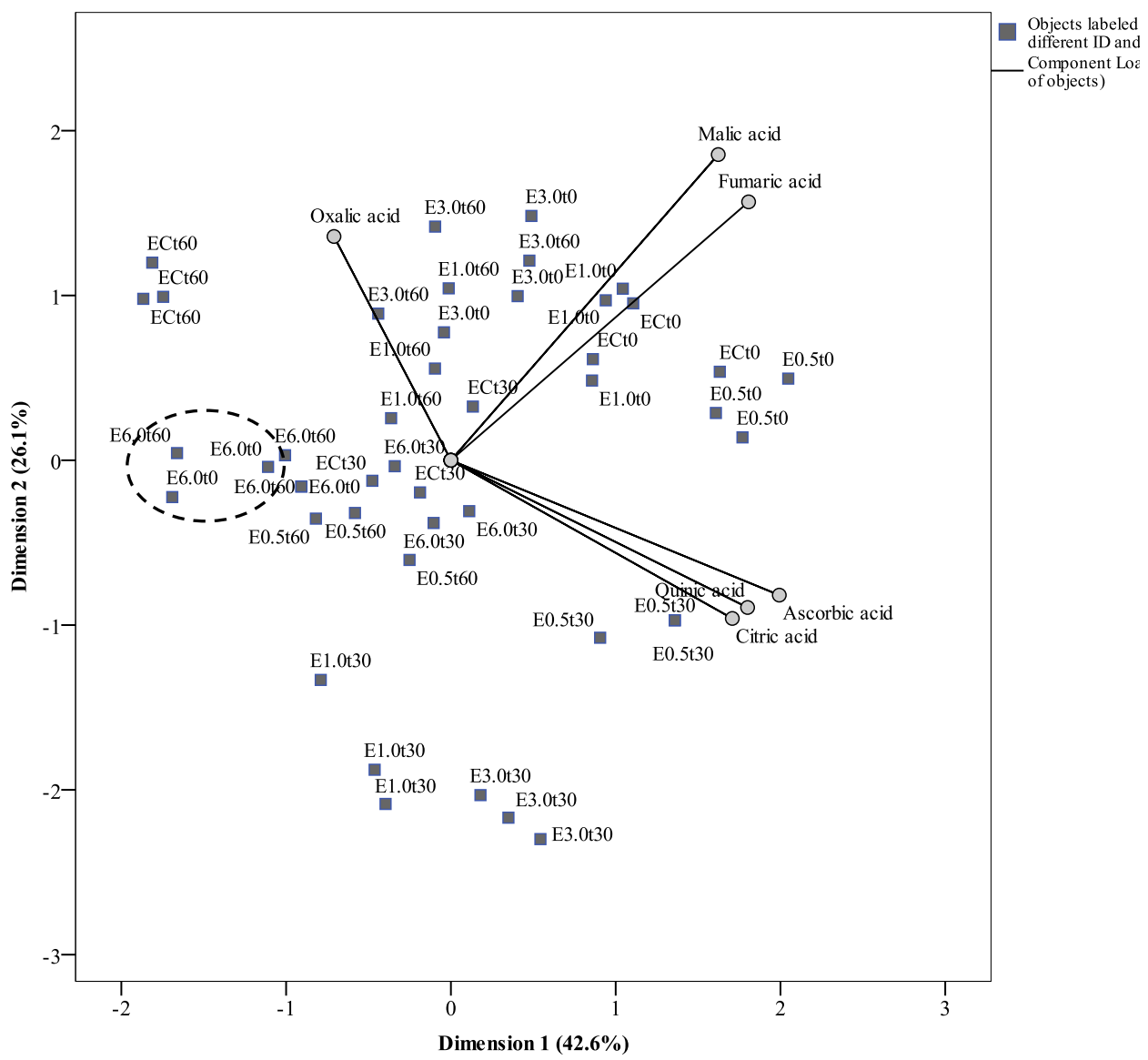

Figure 2. PCA biplot of objects and component loadings. 